\title{
ANALISIS MANAJEMEN RISIKO PROYEK YANG BERPENGARUH TERHADAP WAKTU PELAKSANAAN PROYEK PEMBANGUNAN HOTEL QUEST BY ASTON SEMARANG
}

\author{
Muhammad Hartanto \\ Program Studi Teknik Sipil, Fakultas Teknik, Universitas PGRI, Semarang \\ antokjono02@gmail.com \\ Putri Anggi Permata Suwandi \\ Program Studi Teknik Sipil, Fakultas Teknik, Universitas PGRI, Semarang \\ putrianggi.permata2@upgris.ac.id \\ Donny Ariawan \\ Program Studi Teknik Sipil, Fakultas Teknik, Universitas PGRI, Semarang \\ dyaria77@gmail.com
}

\begin{abstract}
Abstrak
Permasalahan dalam penelitian ini adalah 1) Bagaimana mengidentifikasi penyebab risiko dalam kegiatan konstruksi pembangunan Hotel Quest by Aston Semarang?, 2) Bagaimana menganalisis risiko-risiko yang paling berpengaruh terhadap kerugian dan keterlambatan proyek pembangunan Hotel Quest by Aston Semarang?, 3) Bagaimana durasi waktu dan penjadwalan pelaksanaan pekerjaan proyek tersebut?, dan 4) Risiko apa saja yang berpengaruh dan bagaimana cara penanganannya?. Tujuan penelitian ini adalah; 1) untuk mengidentifikasi penyebab risiko dalam kegiatan konstruksi pembangunan Hotel Quest by Aston, 2) untuk menganalisis dan membuktikan risikorisiko yang paling berpengaruh terhadap kerugian dan keterlambatan proyek pembangunan Hotel Quest by Aston Semarang, 3) untuk menganalisis dan membuktikan peringkat agen risiko apa saja yang paling berpengaruh kemudian memberikan usulan penanganan (aksi mitigasi).

Penelitian ini menggunakan dua data yaitu data primer dan data sekunder. Data primer diperoleh dengan metode pengumpulan data berupa wawancara, kuesioner dan studi lapangan. Sedangkan data sekunder diperoleh dengan data literatur dan data proyek. 10 faktor risiko dominan yang berpengaruh terhadap waktu pembangunan proyek Hotel Quest by Aston adalah ketersediaan material, kekurangan tempat penyimpanan material, kekurangan tempat pembuangan sampah material, keterlambatan pengiriman material dari suplier, kenaikan harga material, ketidak jelasan pasal-pasal dalam kontrak, dokumen-dokumen yang tidak lengkap, keterlambatan pembayaran oleh owner, perselisihan antara owner dan kontraktor dan keterlambatan pembayaran pada sub-kon melalui kontraktor utama. Saran yang dapat disampaikan adalah memperhatikan dan mencermati keberadaan risiko yang termasuk dalam kategori risiko tinggi sehingga dapat diminimalisir.
\end{abstract}

Kata Kunci: Hotel Quest by Aston, waktu pelaksanaan, risiko.

\begin{abstract}
The problems in this research are 1) How to identify the causes of risk in the construction activities of Quest Hotel By Aston Semarang?, 2) How to analyze the risks that most influence the losses and delays in the Quest Hotel By Aston Semarang construction project?, 3) What is the duration of time. and the scheduling of the project work ?, and 4) What risks are affected and how are they handled?. The objectives of this research are; 1) to identify the causes of risk in Quest by Aston Hotel construction activities, 2) to analyze and prove the risks that most influence the losses and delays in the Quest by Aston Semarang Hotel development project, 3) to analyze and prove the ranking of any risk agent the most influential then provides a proposed treatment (mitigation actions).
\end{abstract}


This study uses two data, namely primary data and secondary data. Primary data obtained by data collection methods in the form of interviews, questionnaires, and field studies. Meanwhile, secondary data were obtained with literature data and project data. The 10 dominant risk factors that affect the construction time of the Quest by Aston Hotel project are the availability of materials, shortage of material storage space, shortage of material waste dumps, late delivery of materials from suppliers, increased material prices, unclear clauses in contracts, documents incomplete, late payment by the owner, disputes between the owner and the contractor and late payments to the sub-con through the main contractor. Suggestions that can be conveyed are to pay attention and pay attention to the existence of risks that are included in the high-risk category so that they can be minimized.

Keywords: Quest Hotel by Aston, implementation time, risk.

\section{PENDAHULUAN}

Sekarang ini pembangunan di berbagai bidang sedang giat dilaksanakan oleh bangsa Indonesia. Dalam pelaksanaan proyek konstruksi dengan tepat waktu, dapat di pastikan menguntungkan kedua belah pihak, oleh sebab itu perusahaan selalu berusaha meminimalkan keterlambatan dengan memilih tindakan koreksi yang perlu dilakukan dan mengambil keputusan berdasarkan analisa dari berbagai faktor keterlambatan. Oleh sebab itu diperlukan kajian untuk mengindentifikasi dan menganalisa faktor-faktor yang mempengaruhi faktor majanemen risiko, baik itu risiko murni, spekulatif, risiko terhadap manusia dan benda maupun risiko fundamental yang berpengaaruh terhadap waktu pelaksanaan proyek (Rahayu, 2001). Secara umum risiko dikaitkan dengan kemungkinan (probabilitas) terjadinya peristiwa diluar yang diharapkan (Soeharto, 1995). Risiko juga dapat diartikan sebagai suatu peristiwa yang memiliki 3 kemungkinan untuk terjadi dan dapat berdampak terhadap kegiatan baik positif maupun negatif (Wideman, 1992).

Dalam mengidentifikasi masalah-masalah manajemen waktu, kita perlu memperhatikan hal-hal berikut: 1) Risiko operasional, yang meliputi: a) Sistem organisasi proyek; b) Sumber daya manusia; c) Keterlambatan supply material; d)Keterbatasan lahan fabrikasi dan gudang material; e) Perbedaan lokasi lahan penyimpanan material; 2) Risiko Finansial yang meliputi keterlambatab pembayaran proyek, dan tingginya suku bunga; 3) Hazard Risk, yang meliputi a) keterbatasan dan kurangnya pelaksanaan K3, dan; b) keterbatasan ramburambu 4) Strategic Risk, yang melipuri perubahan perda dan adanya perubahan design. Hal hal tersebut merupakan hal-hal yang paling berpengaruh pada pelaksanaan suatu proyek and mempengaruhi waktu penyelesaian proyek..

Penelitian ini bertujuan untuk 1) Mengidentifikasi penyebab risiko dalam kegiatan konstruksi pembangunan Hotel Quest by Aston. 2) Menganalisis dan membuktikan risiko-risiko yang paling berpengaruh terhadap kerugian dan keterlambatan proyek pembangunan Hotel Quest by Aston Semarang. 3) Mengetahui durasi waktu dan penjadwalan pelaksanaan pekerjaan proyek tersebut. 4) 
Mengukur risiko yang berpengaruh dan cara penanganannya.

Penelitian ini dibatasi dengan 1) Objek dalam penelitian ini adalah proyek konstruksi Hotel Quest by Aston Semarang, yang berlokasi di Jalan Pemuda Semarang atau lebih tepatnya dikawasan Lawang Sewu Semarang. 2) Responden pada penelitian ini yaitu Project Manager, Site Manager, Site Operational Manager, serta pihak-pihak yang bersangkutan dalam pelaksanaan konstruksi Hotel Quest by Aston. 3) Penelitian ini merujuk pada mengidentifikasi risiko biaya dan waktu proyek pada konstruksi Hotel Quest by Aston.

Sebelumnya telah dilakukan penelitian serupa mengenai penerapan manajemen risiko bermanfaat untuk meningkatkan pemahaman tentang proyek, pemahaman tentang risiko yang dihadapi proyek termasuk dampak - dampaknya serta juga dapat memberikan alasan yang tepat dalam pengambilan keputusan dan kemampuan untuk mengelola risiko secara efisien dan efektif, dan bertujuan unutk memilih pengukuran peringanan risiko, pemindahan risiko dan pemulihan risiko untuk mengoptimalkan kinerja organisasi (Setiawan, Walujodjati, \& Farida, 2014).

Selain itu risiko - risiko yang terdapat pada proyek konstruksi sangat banyak, namun tidak semua risiko tersebut perlu diprediksi dan diperhatikan untuk memulai suatu proyek karena hal itu akan memakan waktu yang lama. Oleh karena itu pihak - pihak di dalam proyek konstruksi perlu untuk memberi prioritas pada risiko - risiko yang penting yang akan memberikan pengaruh terhadap keuntungan proyek (Labombang, 2011).

Analisis risiko merupakan suatu proses dari identifikasi dan penilaian (assessment), sedangkan manajemen risiko adalah respon dan tindakan yang dilakukan untuk memitigasi serta mengontrol risiko yang telah dianalisis.

\section{METODE PENELITIAN}

\section{A. Metode Penelitian}

Pendekatan penelitian adalah rencana konsep dan prosedur untuk penelitian yang mencakup langkah-langkah mulai dari asumsi luas hingga metode terperinci dalam pengumpulan data, analisis, dan interpretasi. Pendekatan ini dipilih dengan mempertimbangkan 1) Sifat masalah penelitian atau masalah yang ditangani, pertanyaan-pertanyaan yang perlu kita jawab; 2) Tujuan dari penelitian; 3) Pengalaman pribadi, keterampilan, sikap, minat, dan lain-lain dari peneliti; 4) Sumber daya - sumber daya yang tersedia; 5) Sensivitas masalah yang dihadapi.

\section{B. Jenis Data}

Data primer yang digunakan adalah data Proyek Pembangunan Hotel Quest by Aston Semarang yang meliputi gambar kerja (shoop drawing), data pekerjaan, data cumulative progress (kurva S) dan sebagainya, dan diperoleh dari konsultas, kontraktor dan pengawas pada proyek dengan cara wawancara, pemberian kuesioner dan studi lapangan secara langsung. 
Data sekunder meliputi data efektifitas penggunaan alat berat, data efisien kinerja pekerja, perkiraan waktu pekerjaan yang diperoleh dari literatur yang berupa referensi dan jurnal, serta wawancara dengan praktisi manajemen proyek.

Menurut Arikunto (2006: 131), sampel adalah sebagian atau sebagai wakil populasi yang akan diteliti yang diambil dari populasi atau jumlah keseluruhan dari satuan-satuan atau individu-individu yang karakteristiknya hendak diteliti yang dituju (Djarwanto, 1994: 420), yaitu seluruh pekerja yang ada pada Proyek Pembangunan Hotel Quest by Aston Semarang, dari pihak kontraktor, maupun manajemen konstruksi, back office maupun lapangan.

Data yang diperoleh akan dianalisis dengan beberapa pengujian dan analisis, yaitu Uji kecukupan data, validitas data, reliabilitas data, analisis tingkat risiko, dan analisis risiko dominan.

\section{Uji Kecukupan Data}

Uji kecukupan data ini bertujuan untuk mengetahui apakah data yang telah diambil sudah mencukupi atau tidak untuk mewakili populasi di suatu tempat, dengan melakukan perhitungan data, maka akan dapat ditentukan berapa banyak jumlah minimal data yang diperlukan. Dalam perhitungan jumlah data minimal digunakan rumus Solvin berikut:

$$
\mathrm{n}=\frac{N}{1+N(e)^{2}}
$$

di mana: $\mathrm{n}$ : Banyaknya sampel yang diambil

e : Batas nilai signifikan atau kesalahan $10 \%$

$\mathrm{N}$ : Jumlah populasi

\section{Uji Validitas Data}

Validitas sendiri berarti suatu ukuran yang menunjukkan bahwa variabel yang diukur memang benar-benar variabel yang hendak diteliti oleh peneliti (Cooper dan Schindler, dalam Zulganef, 2006). Uji validitas dilakukan untuk mengetahui keakuratan atau validitas dari masing-masing pertanyaan pada kuesioner yang telah dibagikan kepada responden. Untuk mencari nilai koefisien, maka peneliti menggunakan rumus korelasi product moment seperti sebagai berikut:

$$
\operatorname{rxy}=\frac{n X Y-\left(\sum X\right)\left(\sum Y\right)}{\sqrt{\left(n \sum X^{2}-\left(\sum X\right)^{2} H\left(n \sum Y^{2}-\left(\sum Y\right)^{2}\right\}\right.}}
$$

di mana:

rxy : Koefisien korelasi variabel X dan Y;

$\mathrm{X}$ : Skor tiap item pertanyaan $(\mathrm{X})$;

$\mathrm{Y}$ : Skor total dari semua pertanyaan (Y);

$\Sigma \mathrm{X}:$ Jumlah skor tiap item pertanyaan;

$\Sigma Y$ : Jumlah skor seluruh item pertanyaan;

$\Sigma \mathrm{X}^{2}$ : Jumlah kuadrat skor pertanyaan (X);

$\Sigma \mathrm{Y}^{2}$ : Jumlah kuadrat skor pertanyaan (Y);

$\mathrm{n}$ : Jumlah responden

Selain dengan perhitungan manual dengan menggunakan rumus diatas, uji validitas juga dapat dilakukan dengan menggunakan perangkat lunak SPSS yang dapat menghemat waktu dan mempermudah penelitian.

\section{E. Uji Reliabilitas Data}

Uji reliabilitas dilakukan untuk mengetahui 
tingkat reliabilitas dari masing-masing jawaban yang ada pada kuesioner. Untuk melakukan uji reliabilitas digunakan alat yaitu perangkat lunak SPSS. Uji Reliabilitas ini dapat juga dirumuskan sebagai berikut :

$$
\mathrm{ri}=\left[\frac{k}{k-1}\right]\left[1-\frac{\sum \sigma b^{2}}{\sigma t^{2}}\right]
$$

Di mana:

ri : Reliabilitas instrumen;

k : Banyaknya butir pertanyaan;

$\Sigma \sigma b^{2}$ : Jumlah varian butir;

$\sigma \mathrm{t}^{2} \quad$ : Jumlah skor total seluruh pertanyaan.

\section{F. Analisis Data}

Analisis risiko dilakukan menggunakan metode Analisis Probability Impact Matrix. Sesuai namanya, dalam pengolahan data ini digunakan bantuan sebuah matrik untuk mengetahui tingkatan risiko masing-masing faktor yang mempengaruhi risiko pada pekerjaan suatu proyek.

Metode Probability Impact Matrix ini hanya bisa digunakan setelah identifikasi risiko selesai dilakukan (Iacob dan Dumbrava, 2013) . Hal ini dilakukan unutk menghindari adanya tidak

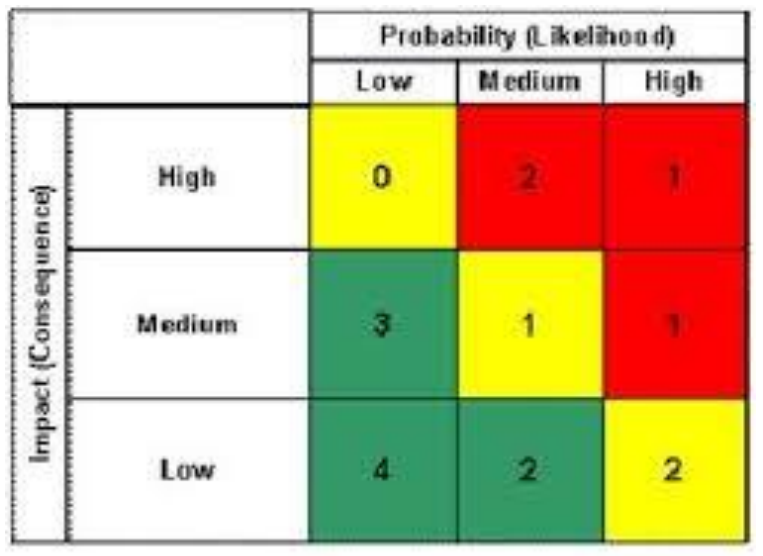

Gambar. 1. Probability Impact Matrix akuratan hasil penelitian yang dikarenakan adanya ketidakvalidan data penelitian atau penyebab lainnya.

Dalam penggunaan matrix tersebut dilakukan perhitungan data untuk pengukuran risiko pekerjaan dengan menggunakan rumus berikut:

$\mathrm{R}=\mathrm{P} \times \mathrm{I}$

Di mana:

$\mathrm{R}=$ Tingkat risiko yang terjadi

$\mathrm{P}=$ Frekuensi (Probability) risiko yang terjadi

$\mathrm{I}=$ Tingkat dampak (Impact) risiko yang terjadi

\section{DATA DAN ANALISIS}

\section{A. Identifikasi Risiko}

Proses identifikasi risiko dilakukan dengan cara membagikan kuesioner untuk melakukan verifikasi, mengklarifikasi dan mengetahui relevan atau tidaknya variabel-variabel risiko yang didapat melalui studi literatur pada proyek yang di tinjau.

Tabel 1. Item kuesioner yang relevan

\begin{tabular}{cl}
\hline \hline No & \multicolumn{1}{c}{ Item Kuesioner } \\
\hline 1 & Ketersediaan material \\
2 & Kekurangan tempat penyimpanan material \\
3 & Kekurangan tempat pembuangan sampah material \\
4 & Keterlambatan pengiriman material dari suplier \\
5 & Kenaikan harga material \\
6 & Kecelakaan dan keselamatan kerja \\
7 & Ketidakjelasan pasal-pasal dalam kontrak \\
8 & Dokumen-dokumen yang tidak lengkap \\
9 & Keterlambatan pembayaran oleh owner \\
10 & Perselisihan antara owner dan kontraktor \\
11 & Keterlambatan pembayaran
\end{tabular}




\begin{aligned} & \hline \hline No \multicolumn{1}{c}{ Item Kuesioner } \\ & \hline 12 Timbulnya kemacetan di sekitar lokasi proyek \\ & 13 Kondisi lokasi site yang sulit \\ & 14 Perbedaan kondisi tanah dasar \\ & 15 Kondisi tanah yang tidak stabil \\ & 16 Meluapnya air tanah \\ & 17 Adanya perubahan desain \\ & 18 Kesalahan estimasi waktu \\ & 19 Keterlambatan kontruksi dari pihak owner \\ & \hline \hline\end{aligned}

Tabel diatas merupakan hasil survei pendahuluan yang dilakukan. Dari seluruh risiko yang diidentifikasi, ada 19 risiko yang relevan dan menjadi penyebab keterlambatan Proyek Pembangunan Hotel Quest by Aston Semarang.

\section{B. Pengujian Data}

Dari hasil pengujian kecukupan data, data yang ada sudah cukup dan dapat dilanjutkan ke pengujian selanjutnya, yaitu pengujian validitas. Pada pengujian validitas pertanyaan ini diperoleh bahwa $\mathrm{r}_{\text {hitung }} \geq \mathrm{r}_{\text {tabel }}$, maka dapat dilanjutkan ke pengujian selanjutnya, yaitu pengujian reliabilitas jawaban. Uji Reliabilitas pada setiap variable menunjukan bahwa seluruh nilai Cronbach Alpha $\geq 0,60$. Sehingga kuisioner masing-masing item pada variable

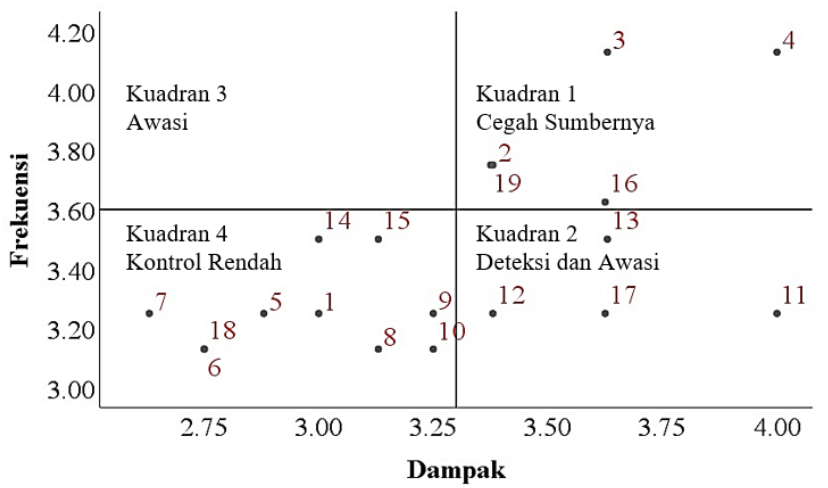

Gambar. 2. Diagram kartesius pengolahan data risiko seluruh kelompok variabel tersebut layak digunakan sebagai alat ukur.

\section{Hasil Penelitian}

Data yang telah diolah kemudian disajikan dalam bentuk diagram kartesius untuk mengetahui tingkat risiko dan aksi mitigasi yang harus dilakukan dari masing-masing faktor yang mempengaruhi waktu pelaksanaan proyek.

Dari diagram kartesius diatas didapat data masing-masing kelompok variabel pertanyaan yang dapat dikelompokkan lagi berdasarkan kelompok variabelnya sebagai berikut:

Tabel 2. Tabel rekapitulasi item material

\begin{tabular}{lll}
\hline \hline No & \multicolumn{1}{c}{ Item Variable } & Keterangan \\
\hline 1 & Ketersediaan material & Kontrol Rendah \\
& Kekurangan tempat & Cegah Sumbernya \\
& penyimpanan material & \\
& Kekurangan tempat & \\
3 & pembuangan sampah & Cegah Sumbernya \\
& $\begin{array}{l}\text { material } \\
4\end{array}$ & Keterlambatan pengiriman \\
& material dari suplier & Cegah Sumbernya \\
5 & Kenaikan harga material & Kontrol Rendah \\
\hline \hline
\end{tabular}

Dari kelima variabel yang berada dalam kelompok variabel material, terdapat tiga variabel yang harus dicegah dari sumbernya untuk meminimalisir terjadinya atau dampak risiko kerja, yaitu keterbatasan tempat penyimpanan material, keterbatasan tempat pembuangan material dan keterlambatan kiriman material oleh supplier. Sedangkan item lainnya hanya perlu dilakukan kontrol biasa.

Tabel 3. Tabel rekapitulasi item kontraktual

\begin{tabular}{ccc}
\hline \hline No & Item Variable & Keterangan \\
\hline 1 & Ketidak jelasan pasal-pasal & Kontrol Rendah
\end{tabular}




\begin{tabular}{|c|c|c|}
\hline No & Item Variable & Keterangan \\
\hline \multicolumn{3}{|c|}{ dalam kontrak } \\
\hline 2 & $\begin{array}{l}\text { Dokumen-dokumen yang tidak } \\
\text { lengkap }\end{array}$ & Kontrol Rendah \\
\hline 3 & $\begin{array}{l}\text { Keterlambatan pembayaran } \\
\text { oleh owner }\end{array}$ & Kontrol Rendah \\
\hline 4 & $\begin{array}{l}\text { Perselisihan antara owner dan } \\
\text { kontraktor }\end{array}$ & Kontrol Rendah \\
\hline 5 & $\begin{array}{l}\text { Keterlambatan pembayaran } \\
\text { pada sub-kontraktor }\end{array}$ & Kontrol Rendah \\
\hline \multicolumn{3}{|c|}{$\begin{array}{l}\text { Seluruh variabel pada kelompok variabel } \\
\text { kontraktual ini hanya memerlukan kontrol yang } \\
\text { rendah untuk meminimalisir risiko pada proyek. }\end{array}$} \\
\hline \multicolumn{3}{|c|}{ Tabel 4. Tabel rekapitulasi item pelaksanaan } \\
\hline No & Item Variable & Keterangan \\
\hline 1 & $\begin{array}{l}\text { Timbulnya kemacetan di } \\
\text { sekitar lokasi proyek }\end{array}$ & Kontrol Rendah \\
\hline 2 & Kondisi lokasi site yang sulit & Kontrol Rendah \\
\hline 3 & $\begin{array}{l}\text { Perbedaan kondisi tanah } \\
\text { dasar }\end{array}$ & Kontrol Rendah \\
\hline 4 & $\begin{array}{l}\text { Kondisi tanah yang tidak } \\
\text { stabil }\end{array}$ & Awasi \\
\hline 5 & Meluapnya air tanah & Kontrol Rendah \\
\hline
\end{tabular}

Pada kelompok variabel pelaksanaan terdapat satu item yang harus diawasi, yaitu kondisi tanah yang tidak stabil yang dapat mempengaruhi proses pelaksanaan proyek, dan dapat menimbulkan kerugian pada seluruh pihak yang terkait dengan Proyek Pembangunan Hotel Quest by Aston Semarang tersebut.

Tabel 5. Tabel rekapitulasi item SDM, desain dan manajemen

\begin{tabular}{lcc}
\hline \hline No & Item Variable & Keterangan \\
\hline 1 & Kesalahan Estimasi Waktu & Kontrol Rendah \\
& Terjadinya keterlambatan & \\
2 & kontruksi dari pihak owner & Kontrol Rendah
\end{tabular}

\begin{tabular}{lll}
\hline \hline No & \multicolumn{1}{c}{ Item Variable } & Keterangan \\
\hline 3 & $\begin{array}{l}\text { Kecelakaan dan } \\
\text { keselamatan kerja }\end{array}$ & Awasi \\
4 & Adanya perubahan desain & Kontrol Rendah
\end{tabular}

Pada kelompok variabel SDM, desain dan manajemen terdapat satu item yang harus diawasi, yaitu tentang kecelakaan dan keselamatan kerja yang dapat mempengaruhi proses pelaksanaan proyek.

\section{Data Ranking}

Dari data yang diperoleh dari perhitungan nilai dari analisis risiko secara keseluruhan dapat diolah kembali untuk diurutkan dari nilai terbesar sampai dengan yang terkecil pada seluruh item pekerjaan yang terdapat pada kuisioner penelitian ini. Hal ini dimaksudkan agar pihak terkait dapat melakukan aksi mitigasi risiko atau pencegahan terjadinya risiko dari faktor yang memiliki dampak risiko tertinggi, sehingga pekerjaan menjadi lebih efisien, karena pengerjaannya dapat di sortir dari prioritasnya.

Dari seluruh data faktor penyebab risiko Proyek Hotel Quest by Aston Semarang dapat diambil 10 faktor yang memiliki risiko dengan dampak paling besar (rangking 10 besar). Data rangking disajikan dalam tabel dibawah ini yang merupakan hasil dari analisis ranking dari seluruh item kuisioner yang diisi oleh responden.

Tabel 6. Tabel rangking 10 variabel berisiko tertinggi

\begin{tabular}{cll}
\hline \hline No & \multicolumn{1}{c}{ Item Variable } & Dampak \\
\hline 1 & Ketersediaan material & Tinggi \\
2 & Kekurangan tempat pembuangan & Tinggi
\end{tabular}


sampah material

Kekurangan tempat penyimpanan material

Keterlambatan pengiriman material dari suplier

Dokumen-dokumen yang tidak lengkap

Perselisihan antara owner dan

kontraktor

Ketidak jelasan pasal-pasal dalam

kontrak

Sedang

Keterlambatan pembayaran oleh owner

10 Perbedaan kondisi tanah dasar

Sedang

Sedang

\section{KESIMPULAN}

Sebagai bagian akhir dalam penelitian, dihasilkan sebuah kesimpulan yang diperoleh dari pengolahan data Analisis risiko, yaitu 1) Terdapat 10 faktor risiko dominan yang berpengaruh terhadap waktu pada proyek pembangunan Hotel Quest by Aston Semarang.

2) Sumber risiko paling dominan yang menjadi risiko tinggi terhadap waktu konstruksi proyek adalah kesalahan asumsi-asumsi teknik pada item material dan risiko kontraktual. 3) Lamanya waktu penyelesaian proyek Hotel Quest by Aston Semarang berpengaruh besar dan pertambahan biaya proyek.

Dengan telah teridentifikasinya risiko-risiko yang berdampak besar terhadap waktu penyelesaian proyek, maka seluruh pihak yang terkait dalam proyek harus memperhatikan dan mencermati keberadaan risiko agar dapat mencegah timbulnya risiko tersebut secepat mungkin.
Adanya risiko keterlambatan pembayaran dari owner, pembuatan kontrak jangka panjang antara kontraktor dan suplier dapat digunakan untuk menghindari adanya kenaikan harga material yang dapat menimbulkan kerugian, terutama di pihak kontraktor.

\section{DAFTAR PUSTAKA}

Arikunto, S. (2006). Prosedur Penelitian suatu Pendekatan Praktik, Edisi Revisi VI . Jakarta: PT. Rineka Cipta.

Cooper, D.R., dan Schindler, P.S. (2006). Business Research Methods. USA: McGraw-Hill.

Djarwanto, P., S. (1996). Statistik Induktif. Yogyakarta: BPFE.

Dumbrava, V., \& Iacob, V. S. (2013). Using probability-impact matrix in analysis and risk assessment projects. Journal of knowledge management, economics and information technology, 76-96.

Labombang, M. (2011). Manajemen Risiko pada Proyek Konstruksi. Jurnal SMARTek Vol.9 No.1 , 39-46.

Rahayu, P.H. (2001). Asuransi Contractor's All Risk sebagai Alternatif Pengalihan Risiko Proyek Dalam Industri Konstruksi Indonesia. Seminar Nasional Manajement Konstruksi 2001. Fakultas Teknik Universitas Katolik Parahyangan. Bandung.

Setiawan, A., Walojodjati, E., \& Farida, I. (2014). Analisis Manajemen Risiko pada Proyek Pembangunan Jalan Tol Cisumdawu (Studi Kasus: Development of Cileumyi Sumedang Dawuan Toll Road Phase I). Jurnal Konstruksi STT Garut Vol. 11 No. 1, $1-11$.

Soeharto, I. (1995). Manajemen Proyek dari konseptual sampai operasional. Jakarta: Erlangga.

Wideman, M. R. (1992). Project and Program Risk Management: A Guide to Managing Project Risks and Opportunities (PMBOK Handbooks). Philadelphia: Project Management Institute. 